\title{
Correction to: A Multi Recipient Aggregate Signcryption Scheme Based on Elliptic Curve
}

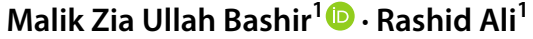 \\ Published online: 17 August 2021 \\ (c) Springer Science+Business Media, LLC, part of Springer Nature 2021
}

\section{Correction to: Wireless Personal Communications (2020) 115:1465-1480 https://doi.org/10.1007/s11277-020-07637-z}

This article was incorrectly published with the short name of the first author (Malik Zia) instead of the full name (Malik Zia Ullah Bashir). The original article has been corrected.

Publisher's Note Springer Nature remains neutral with regard to jurisdictional claims in published maps and institutional affiliations.

The original article can be found online at https://doi.org/10.1007/s11277-020-07637-z.

Malik Zia Ullah Bashir ziamalik199@gmail.com

Rashid Ali

rashid.ali@cust.edu.pk

1 Department of Mathematics, Capital University of Science and Technology, Islamabad, Pakistan 